\title{
Early extubation after cardiac surgery: The evolution continues
}

\author{
Hilary P. Grocott, MD, FRCPC, FASE
}

From the Department of Anesthesia, University of Manitoba, Winnipeg, Manitoba, Canada.

Disclosures: Author has nothing to disclose with regard to commercial support.

Received for publication June 22, 2017; accepted for publication July 17, 2017; available ahead of print Aug 10, 2017.

Address for reprints: Hilary P. Grocott, MD, FRCPC, FASE, University of Manitoba, CR3008, 369 Tache Ave,

Winnipeg R2H 2A6, Manitoba, Canada (E-mail: hgrocott@sbgh.mb.ca).

J Thorac Cardiovasc Surg 2017;154:1654-5

$0022-5223 / \$ 36.00$

Copyright (C) 2017 by The American Association for Thoracic Surgery

http://dx.doi.org/10.1016/j.jtcvs.2017.07.025

Just as cardiovascular surgery has continually evolved through the years, so has the practice of cardiac anesthesia. Long gone are the days of high-dose, opiate-based anesthesia, once thought to be beneficial to patients in blunting the stress response to surgery and avoiding hemodynamic instability. Indeed, fundamental changes in anesthetic management started decades ago, when the concept of fast-track cardiac anesthesia first appeared in the literature. ${ }^{1}$ This was a revolutionary concept, as patients previously were routinely ventilated for as long as 12 to 24 hours after even the most routine cardiac surgery. Since that time, however, a number of groups have continued to reduce the time to extubation, ${ }^{2}$ and the term ultrafast cardiac anesthesia is now considered to be defined by extubation in the operating room itself.

Coincident with changes in anesthetic techniques that have allowed the very early extubation of patients, there has also been a change in the characteristics of patients undergoing cardiac surgery. It is well known that patients are now much older and sicker that they were in the past. Furthermore, advances in percutaneous coronary intervention have considerably reduced the number of patients who are candidates for cardiac surgery, often leaving us to operate on the frailest and sickest patients, and those with the most complex coronary anatomy. As such, tools are needed to aid in identifying the patients who would optimally be chosen for early extubation, and that is what Subramaniam and colleagues ${ }^{3}$ have accomplished with their development of a predictive score for successful extubation, as published in this issue of the Journal. The characteristics are in some respects very obvious (eg, younger age and simpler operation); however, one can easily make the argument that all patients, irrespective of the procedure or the patient characteristics, should be treated right from the start as if they can be extubated in the operating room. The decision to extubate patients should likely be made once the operation is nearing completion, in part informed by the overall success of the operation. The many nuances and complications

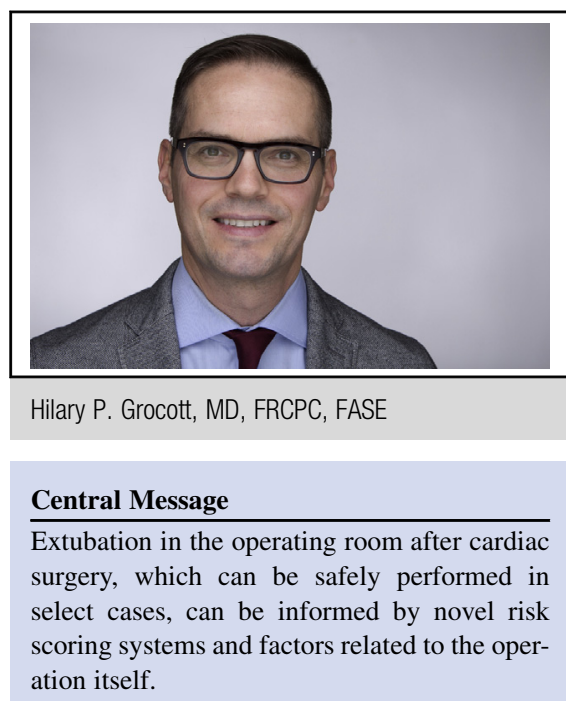

See Article page 1656.

that may have occurred during the procedure (eg, significant residual myocardial dysfunction or incomplete revascularization, coagulopathy, or other coinciding end-organ dysfunction, such as acute lung injury) should all factor into the decision whether extubation in the operating room is possible.

Surgeons need to understand that the angst regarding the initial safety of fast-track cardiac anesthesia (when patients were extubated within 6-8 hours of cardiac surgery) quickly went away once the advantages of early extubation were appreciated. Indeed, it can be just as safe to do this immediately in the operating room with the right types of patients. Furthermore, there is even some evidence that suggests that these patients who are extubated early may have fewer postoperative complications, including postoperative delirium. ${ }^{4}$ Clearly not all patients will be appropriate for extubation in the operating room-for example, patients with significant obstructive sleep apnea, for whom residual opiates may further complicate the apnea, would not be ideal candidates. ${ }^{5}$ Risk scoring systems such as that outlined by Subramaniam and colleagues, ${ }^{3}$ however, will help guide these decisions.

In summary, cardiac surgery will continue to evolve, with the boundaries of what is possible continually being pushed. So too will the practice of cardiac anesthesia, including the potential for extubating in the operating room. 


\section{References}

1. Cheng D, Karski J, Peniston C, Raveendran G, Asokumar B, Carroll J, et al. Early tracheal extubation after coronary bypass graft surgery reduces costs and improves resource use. A prospective, randomized, controlled trial. Anesthesiology. 1996; 85:1300-10.

2. Nicholson DJ, Kowalski SE, Hamilton GA, Meyers MP, Serrette C, Duke PC. Postoperative pulmonary function in coronary artery bypass graft surgery patients undergoing early tracheal extubation: a comparison between short-term mechanical ventilation and early extubation. J Cardiothorac Vasc Anesth. 2002;16:27-31.

3. Subramaniam K, DeAndrade D, Mandell D, Althouse AD, Manmohan R, Esper SA, et al. Predictors of operating room extubation in adult cardiac surgery. J Thorac Cardiovasc Surg. 2017;154:1656-65.

4. Arenson BG, MacDonald LA, Grocott HP, Hiebert BM, Arora RC. Effect of intensive care unit environment on in-hospital delirium after cardiac surgery. $J$ Thorac Cardiovasc Surg. 2013;146:172-8.

5. Liu FL, Cherng YG, Chen SY, Su YH, Huang SY, Lo PH, et al. Postoperative recovery after anesthesia in morbidly obese patients: a systematic review and metaanalysis of randomized controlled trials. Can J Anaesth. 2015;62:907-17. 